\title{
ESQUISTOSSOMOSE MANSONI NO SUDOESTE DO ESTADO DE MINAS GERAIS (BRASIL)*
}

\author{
Omar dos Santos Carvalho** \\ Cristiano Lara Massara** ○ \\ Roberto Sena Rocha** \\ Naftale Katz**
}

\begin{abstract}
Carvalho, O. dos S. et al. Esquistossomose mansoni no sudoeste do Estado de Minas Gerais (Brasil). Rev. Saúde públ., S. Paulo, 23:341-4, 1989.

RESUMO: É descrito un foco de esquistossomose mansoni, no Municipio de Passos, sudoeste do Estado de Minas Gerais, região até agora considerada livre da endemia. Relata-se a presença de Bıomphalaria glabrata parasitada por Schistosoma mansonı, em um clube campestre, nas imediaçoes da cidade, alèm de quatro crianças, residentes" neste clube, com esquistossomose autóctone. Observa-se ainda, a existência de B. straminea, não infectada, nos tanques da Estação de Hidrobiologia e Piscicultura de Furnas. É discutida a importância epidemiológica da esquistossomose para a região.
\end{abstract}

DESCRITORES: Esquistossomose mansônica, incidência. Bıomphalarıa, parasitologia.

\section{INTRODUÇÃO}

A esquistossomose mansoni é uma doença em expansão em algumas regiões do Brasil2, em que pese os conhecimentos adquiridos nos últimos anos, relacionados, sobretudo, ao seu diagnóstico e tratamento.

Fenômeno semelhante tem sido observado no Estado de Minas Gerais onde a esquistossomose mansoni vem lenta, mas progressivamente se expandindo, para regiões, até recentemente, consideradas indenes. De fato, focos da parasitose foram identificados nas cidades de Itajubá, no Sul do Estado3,5,10,12, e em Paracatu, na região Noroeste $e^{5,6}$.

A presente comunicação objetiva divulgar os dados sobre um novo foco de esquistossomose no Município de Passos, sudoeste do Estado de Minas Gerais, região até agora considerada indene para a doença.

\section{MATERIAL E MÉTODOS}

No primeiro semestre de 1987 , atendendo recomendação do Programa de Controle da Esquistossomóse no Estado de Minas Gerais9, o Centro Regional de Saúde de Passos notificou a ocorrência, nessa cidade, de um caso de esquis- tossomose. Tratava-se de uma criança do sexo feminino, com dez anos de idade cuja infecção teria sido adquirida na própria cidade. O Município de Passos, localizado na região sudoeste do Estado de Minas Gerais, é banhado pelo rio Grande, possui cerca de 80.000 habitantes, e dista aproximadamente $355 \mathrm{~km}$ de Belo Horizonte.

As informações obtidas junto a referida criança direcionaram os trabalhos para um clube campestre, existente nas imediações da cidade, onde possivelmente teria ocorrido a infecção.

Foi realizado um levantamento malacológico nas coleções hídricas existentes dentro da área do clube, bem como na Estação de Hidrobiologia e Piscicultura de Furnas, localizada às margens do rio Grande, à jusante da represa e a $\mathbf{3 0}$ $\mathrm{km}$ de Passos.

Os moluscos capturados com ajuda de concha metálica foram devidamente acondicionados e examinados em laboratório, com auxílio de microscópio estereoscópico, após compressão entre plàcas de vidro.

O diagnóstico parasitológico, realizado pelo método de Kato-Katz"', examinando-se duas lâminas de cada amostra, abrangeu 329 crianças de três escolas de $1^{\circ}$ grau, além de 7 pessoas residentes no interior do clube.

* Trabalho parcialmente financiado pelo Conselho Nacional de Desenvolvimento Científico e Tecnológico (CNPq) (PIDE IV - Processo 40.0740/85).

** Centro de Pesquisas René Rachou/FIOCRUZ - Caixa Postal 1743 - 30190 - Belo Horizonte, MG - Brasil. 


\section{RESULTADOS}

O levantamento malacológico no interior do clube possibilitou a coleta de 404 exemplares de Biomphalaria glabrata, sendo que $193(47,8 \%)$ originários de uma única vala. O exame revelou $9(2,2 \%)$ moluscos, coletados nessa vala parasitados por Schistosoma mansoni. Foi ainda observada a presença de fisídeos na área.

Nos tanques da Estação de Hidrobiologia e Piscicultura foram capturados 501 exemplares de $B$. straminea, todos negativos para cercárias e/ou esporocistos de S.mansoni.

O diagnóstico parasitológico identificou 1 $(0,3 \%)$ escolar parasitado por $S$. mansoni, não sendo possivel afirmar tratar-se de caso autóctone.Entre as sete pessoas residentes no interior do clube, seis apresentaram ovos do parasita nas fezes, sendo que, quatro eram crianças e nunca haviam se ausentado da cidade.

\section{COMENTÁRIOS}

Os dados obtidos permitem afirmar que está ocorrendo transmissão do $S$. mansoni no Município de Passos, constituindo-se no primeiro relato de esquistossomose mansoni autóctone, no Sudoeste do Estado de Minas Gerais.

Confinada, principalmente, em larga faixa do Norte, Nordeste e parte da região Leste do Estado, a esquistossomose vem sendo disseminada para outras áreas, condicionada por correntes migratórias a procura de melhores condições de vidal.

Em Passos, é relevante apontar para o número de migrantes, em sua grande maioria do próprio Estado, oriundos muitas vezes de regiões com esquistossomose, que para alí tem-se dirigido, sobretudo por ocasião da colheita do café, produto de cultura relativamente recente no Município.

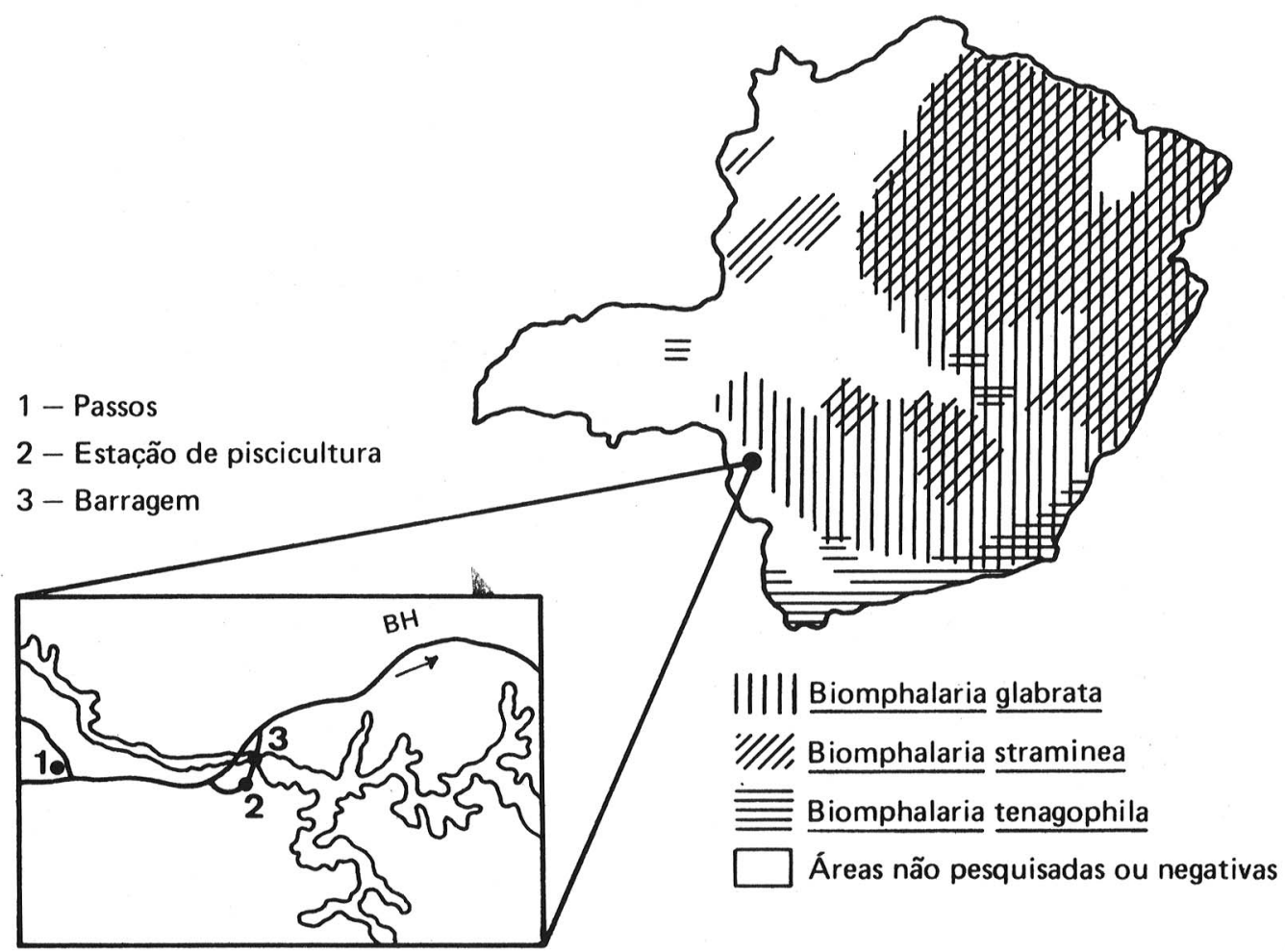

Área do reservatório de Furnas

Figura - Mapa de distribuição dos hospedeiros intermediários do Schistosoma mansoni no Estado de Minas Gerais (Paraense ${ }^{13}, 1986$, atualizado pelos Autores). Em detalhe a localização do reservatório da hidrelétrica de Furnas. 
Outro fato de importância, verificado na região, foi a presença de B.straminea nos tanques da Estação de Hidrobiologia e Piscicultura de Furnas. Anteriormente, entre março/78 e janeiro/79, a B.tenagophila também já havia sido observada no interior dos referidos tanques*. Ao que tudo indica, estas espécies não são autoctónes da área ${ }^{13}$, tendo sido, provavelmente, introduzidas com peixes trazidos de outras regiōes $4.5,7,8$.

Este fato tem grande importância epidemiológica pois, por este mecanismo, planorbíneos podem estar sendo transportados e disseminados para as mais diversas regiões do país.

Algumas recomendações foram feitas às autoridades sanitárias visando o controle da esquistossomose na área, tais como:

1. tratamento de todos os pacientes com esquistossomose;

2. canalização ou eliminação da vala no interior do clube;

3. eliminação das coleções hídricas que não possuem utilidade para o clube;

4. aplicação de moluscicida nas coleções hídricas, no interior do clube, até que sejam realizadas as medidas sugeridas;

5. eliminação dos moluscos dos tanques da Estação de Hidrobiologia e Piscicultura de Furnas;

6. colocação em quarentena dos peixes a serem transportados ou que venham de outras regiões, e finalmente;
7. realização periódica de pesquisas nas estações de piscicultura, com o objetivo de identificar a presença de planorbídeos.

A ocorrência de esquistossomose mansoni no sudoeste do Estado de Minas Gerais, em área adjacente ao reservatório de Furnas (Fig.), é um fato preocupante e merece estudos mais acurados e uma vigilância epidemiológica sistematizada. De fato, caso este reservatório venha a se constituir em foco de esquistossomose, seu controle se tornará difícil, ou mesmo impossivel de ser realizado.

\section{AGRADECIMENTOS}

Ao Dr. Wladimir Lobato Paraense do Instituto Oswaldo Cruz (FIOCRUZ) pela identificação dos planorbídeos, aos Drs. Edson Perini, José Ernani Silveira, Zeine Esper El-Maleh, Silvana Aparecida Gonçalves e aos Srs. Jovane Neperson de Souza e Benedito Chagas (Secretaria de Saúde do Estado de Minas Gerais) pelas informações e facilidades durante a realização dos trabalhos. Ao Dr. Dirceu Marzulo Ribeiro pelas facilidades oferecidas na Estação de $\mathrm{Hi}$ drobiologia e Piscicultura de Furnas. Aos Srs. José Geraldo Amorim da Silva e Antônio Carlos do Prado (Centro de Pesquisas René Rachou - FIOCRUZ) pela assistência técnica.

CARVALHO, O. dos S. el al. [Schistosomiasis mansoni in the Southwest of the Stale of Minas Gerais (Brazil)]. Rev. Saúde públ., S. Paulo, 23:341-4, 1989

\begin{abstract}
A new focus of schistosomiasis nansoni at Passos, a lown in the Southwest of the State of Minas Gerais (Brazil), region until now considered free of the disease is reported. Malacological surveys showed Bıophalaria glabrata naturally infected with Schistosoma manson in a country club near Passos. All $B$. strammea captured at the pisciculture station of the Furnas hydroeletric dam were negative. Six out of seven individuals living in the country club were found to be infected with $S$. mansom, including four children who had never been out of Passos. The epidemiological importance of these findings is discussed.
\end{abstract}

KEYWORDS: Schistosomiasis mansoni, occurrence. Biomphalaria, parasitology.

* Relatório: "Levantamento da Malacofauna Dulcícola do Reservatório da Us.F.O." elaborado por Maria Helena Rodrigues Oliveira (UFJR). Esıação de Hidrobiologia e Piscicultura de Furnas. (Dados inéditos). 


\section{REFERENCIAS BIBLIOGRÁFICAS}

1. BARRETO, M.P. Movimentos migratórios e sua importância na epidemiologia de doenças parasitárias no Brasil. Rev. Soc. bras. Med. trop.,1: 91-102, 1967.

2. BINA, J.C. A expansão da esquistossomose mansoni no Brasil: fatores determinantes e sugestões para o seu controle. Rev. méd. Bahia, 22: 86-100. 1967.

3. CARVALHO, O.S.; SOUZA, C.P.; KATZ, N. Primeiro encontro de Biomphalaria tenagophila (d'Orbigny, 1835) naturalmente infectada, com Schistosoma mansoni, em Itajubá, Sul do Estado de Minas Gerais, Brasil. Rev. Saúde públ., S. Paulo, 19: 8891, 1985.

4. CARVALHO, O.S.; GUIMARÃES, C.T.; MASSARA, C.L.; BONÉSIO, J.E.R. Situação atual da esquistossomose mansoni no Lago da Pampulha, Belo Horizonte, MG, Brasil. Rev. Saúde públ., S. Paulo,19: 270-7, 1985.

5. CARVALHO, O.S.; ROCHA, R.S.; MASSARA, C.L.; KATZ, N. Expansão da esquistossomose mansoni em Minas Gerais. Mem. Inst. Oswaldo Cruz, 82(Supl. 4): 295-8, 1987. [Apresentado ao International Symposium on Schistosomiasis/1: Reunião Nacional de Esquistossomose, Rio de Janeiro, 1987.

6. CARVALHO, O.S.; ROCHA, R.S.; MASSARA, C.L.; KATZ, N. Primeiros casos autóctones de esquistossomose mansoni no Município de Paracatu, Noroeste do Estado de Minas Gerais (Brasil). Rev. Saúde públ., S. Paulo, 22:237-9, 1988. [Apresentado ao $22{ }^{\circ}$ Congresso da Sociedade Brasileira de Medicina Tropical/ 4? Congresso da Sociedade Brasileira de Infectologia, Curitiba, PR, 1987.

7. CORREA, L.L.; CORREA, M.O.A.; VAZ, J.S.; SILVA, M.I.P.G.; SILVA, R.M.: YAMANAKA, M.T. Importância das plantas ornamentais dos aquários como veículos de propagação de vetores de Schisto. soma mansoni. Rev. Inst. Adolfo Lutz, 40: 89-96, 1980.
8. CORREA, R.R.; MURGEL, G.M.T.; PIZA, J.T.; RAMOS, A.S.; DIAS, L.C.S.; MORAES, L.V.C.; ROSÁRIO, F.F. Dispersão de Biomphalaria straminea, hospedeira intermediária do Schistosomo mansoni, através da distribuição de peixes. Rev. Saúde públ., S.Paulo, 4: 117-27, 1970.

9. KATZ, N.Controle da esquistossomose no Estado de Minas Gerais. In: Reis, F.A.; Faria, I.I.; Katz, N. Modernos conhecimentos sobre esquistossomose mansônica. Belo Horizonte, Academia Mineira de Medicina, 1986. p. 51-66. [Suplemento dos Anais da Academia Mineira de Medicina, 1983/1984].

10. KATZ, N. \& CARVALHO, O.S. Introdução recente da esquistossomose mansoni no Sul do Estado de Minas Gerais, Brasil. Mem. Inst. Oswaldo Cruz, 7:281-4, 1983.

11. KATZ, N.; CHAVES, A.; PELlEGRINO, J. A simple device for quantitative stool thick-smear technique in schistosomiasis mansoni. Rev. Inst. Med. Trop. S.Paulo, 14: 397-400, 1972.

12. LAMBERTUCCI, J.R.; ROCHA R.S.; CARVALHO, O.S.; KATZ, N. A esquistossomose mansoni em Minas Gerais. Rev. Soc. bras. Med. trop., 20:4752, 1987.

13. PARANAENSE, W.L. Distribuição dos caramujos no Brasil. In: Reis, F.A.; Faria I.I.; Katz, N. Modernos conhecimentos sobre esquistossomose mansônica. Belo Horizonte, Academia Mineira de Medicina, 1986. p. 117-28 [Suplemento dos Anais da Academia Mineira de Medicina, 1983/1984].

Recebıdo para publicação em 14/12/1988. Reapresentado em 1/6/89.

Aprovado para publicação em $7 / 6 / 89$. 